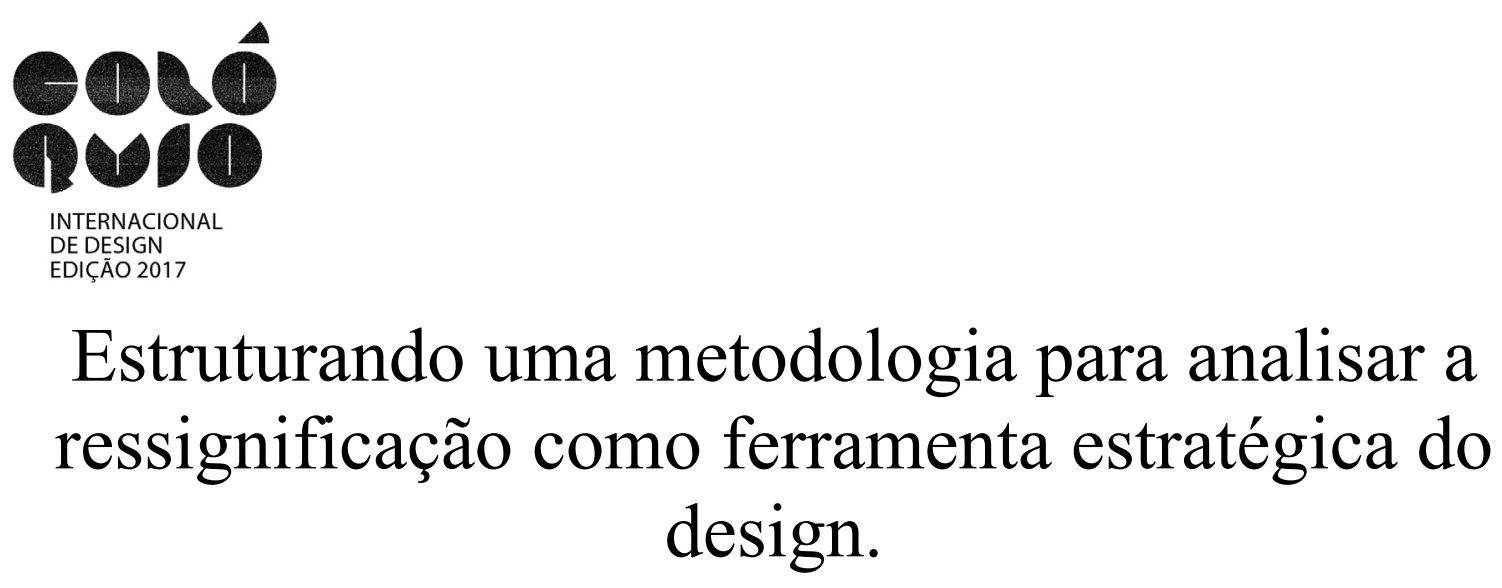

Camilo Belchior;

Rita Aparecida da Conceição Ribeiro

resumo:

Várias inovações atreladas ao design estão sendo desenvolvidas ao longo de décadas e muitas estão ligadas direta ou indiretamente a questões da significação, ou melhor, à relação de sentidos ou significados que atribuímos aos objetos, artefatos ou as coisas de um modo geral. Pensar que, se podemos atribuir sentidos, podemos também alterá-los de sua significação inicial, nos abre um leque infinito de possibilidades para o design. Neste contexto, ressignificar é proporcionar um novo sentido ao objeto, alterando seu conceito, sua percepção ou interpretação original. É tornar o objeto coerente para o sujeito, sob novo ponto de vista, transformando-o para o contexto vigente. Refletir sobre esta questão nos levou a acreditar que a ressignificação possa ser também entendida como uma ferramenta para o design, atribuindo-Ihe mais elementos estratégicos. O estudo da ressignificação como ferramenta estratégica do design é o tema central da tese de doutorado de Camilo Belchior e este artigo versa sobre como foi estruturada a metodologia do seu trabalho. Portanto, pretendemos trabalhar nas possibilidades de intervenção do design, usando a ressignificação de forma estratégica para atuar na autoestima destas crianças portadoras de algum tipo de deficiência física, nos seus familiares e seus cuidadores (profissionais de reabilitação). Nossa proposta é pensar em outro tipo de atuação do design, no campo das práticas de inclusão social, voltado à construção de artefatos que são indispensáveis às pessoas com deficiências, ressignificando estes artefatos (estabilizadores, andadores, muletas, cadeiras de roda, órteses, etc), promovendo assim o aumento da autoestima de seus usuários, familiares, bem como dos profissionais que lidam diariamente com estas crianças.

palavras-chave:

Ressignificação; Design; Significação; Estratégia; Percepção 


\section{Em busca de um novo paradigma}

Várias inovações atreladas ao design estão sendo desenvolvidas ao longo de décadas e muitas estão ligadas direta ou indiretamente a questões da significação, ou melhor, à relação de sentidos ou significados que atribuímos aos objetos, artefatos, as coisas de um modo geral. Pensar que, se podemos atribuir sentidos, podemos também alterá-los de sua significação inicial, nos abre um leque infinito de possibilidades para o design.

As formas dos artefatos não possuem um significado fixo, mas antes são expressivas de um processo de significação, ou seja, a troca entre aquilo que está embutido em sua materialidade e aquilo que pode ser depreendido delas por nossa experiência. (CARDOSO, 2013, PAG.36)

Neste contexto, ressignificar é proporcionar um novo sentido ao objeto, alterando seu conceito, sua percepção ou interpretação original. É tornar o objeto coerente para o sujeito, sob novo ponto de vista, transformando-o para o contexto vigente.

Refletir sobre esta questão nos levou a acreditar que a ressignificação possa ser também entendida como uma ferramenta para o design, atribuindo-lhe mais elementos estratégicos.

Partindo desta interpretação, entendemos que o design tem a função natural de significar e também a de ressignificar elementos, símbolos, valores, atributos e usos às coisas que fazem parte do universo humano. A geração de significados, origem da palavra design (de: a partir do / sign: signo), ou a sua alteração (ressignificação), pode contribuir para a geração de ações estratégicas que resultem em produtos ou serviços com significados completamente novos e diferentes do seu original, que por sua vez, se tornarão atraentes e desejados aos olhos do seu espectador, modificando parcial ou completamente a percepção que temos sobre algo ou alguma coisa.

Como exemplo, citamos o case dos relógios SWATCH, do livro de Verganti (2012), no qual a estratégia adotada pela marca conseguiu fazer uma inovação radical de significados ao propor o uso do relógio não apenas como uma máquina para administrar o tempo, mas, além disto, um acessório pessoal que explicita o seu estilo de vida, ação que em 1987 proporcionou a empresa a venda de 8 milhões de relógios, apenas 1 ano após seu lançamento.

Em meados dos anos 1980, com a invenção da tecnologia do uso de quartzo, os líderes de mercado de relógios, como Seiko e a Casio, acreditavam que as pessoas viam relógios como instrumentos técnicos, e, por isso, concentravam-se em adicionar novas funções aos relógios. Entretanto, as pessoas começaram a ver relógios como acessórios de moda: independente de características e precisão, elas estavam mais interessadas em colecionar vários modelos que combinassem com estilos de roupas, trocando-os a cada estação, assim como faziam com sapatos e chapéus. Um produto inovador provocou essa mudança radical nesse mercado: um relógio introduzido pela empresa suíça Swatch em 1986.(VERGANTI, 2012,Pag.16).

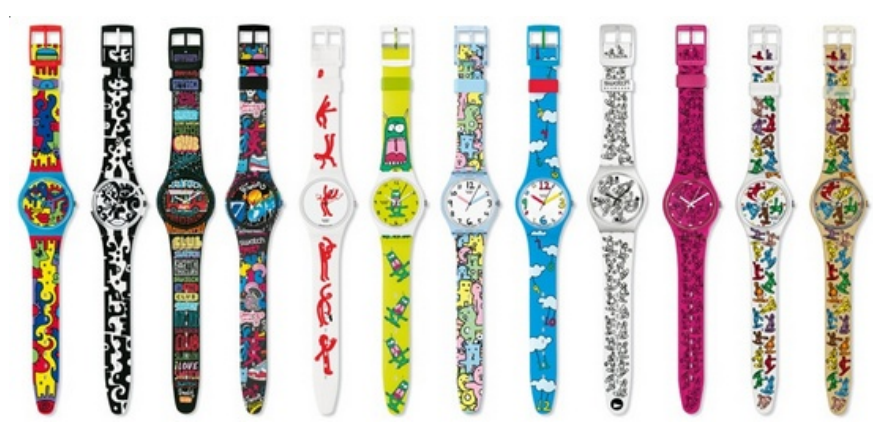

Fig.1 Relógios Swatch 1980 - Fonte: do autor 
A globalização cultural e o desenvolvimento de diversas inovações tecnológicas, como a que acabamos de citar, desencadearam fatores importantes no desempenho da economia, refletindo diretamente na evolução das atividades do design, colocando-o numa situação privilegiada, que possibilita sua maior atuação na gestão de empresas, instituições, projetos, etc. A consequência disto é uma alteração progressiva na forma de pensar da humanidade, principalmente relacionada aos seus desejos pessoais e a sua visão de consumo.

Mas a relação do homem com os objetos é mais do que uma simples relação de consumo. É possível que em determinadas situações, o diferencial de qualidade, estética e técnica dos produtos esteja legado a segundo plano e o mais importante sejam as experiências e sensações que eles podem produzir em cada um de nós. Sudjic aponta que:

Quando se olha para a história do século XX, não se discute que a peça de design de automóveis mais significativa tenha sido o lançamento, em 1908, do FORD modelo T, que permaneceu em produção pelas duas décadas seguintes. Mas é provável que, em alguns aspectos, o Nissan Figaro, exposto pela primeira vez no salão do automóvel de Tóquio em 1989, e do qual só foram feitas 20 mil unidades, tenha sido igualmente significativo - não devido a razões mecânicas ou técnicas, mas sim porque, pela primeira vez na história do design automobilístico, o automóvel era tratado não como peça séria de tecnologia, mas sim como brinquedo. (SUDJIC, 2010, p. 46).

Com esta colocação, Sudjic indica que o mesmo artefato teve significações completamente distintas umas das outras, despertando nos consumidores o desejo de adquiri-lo por ter criado percepções diferentes daquela originalmente atribuída, o seja, de veículo automotor para um brinquedo de adultos.

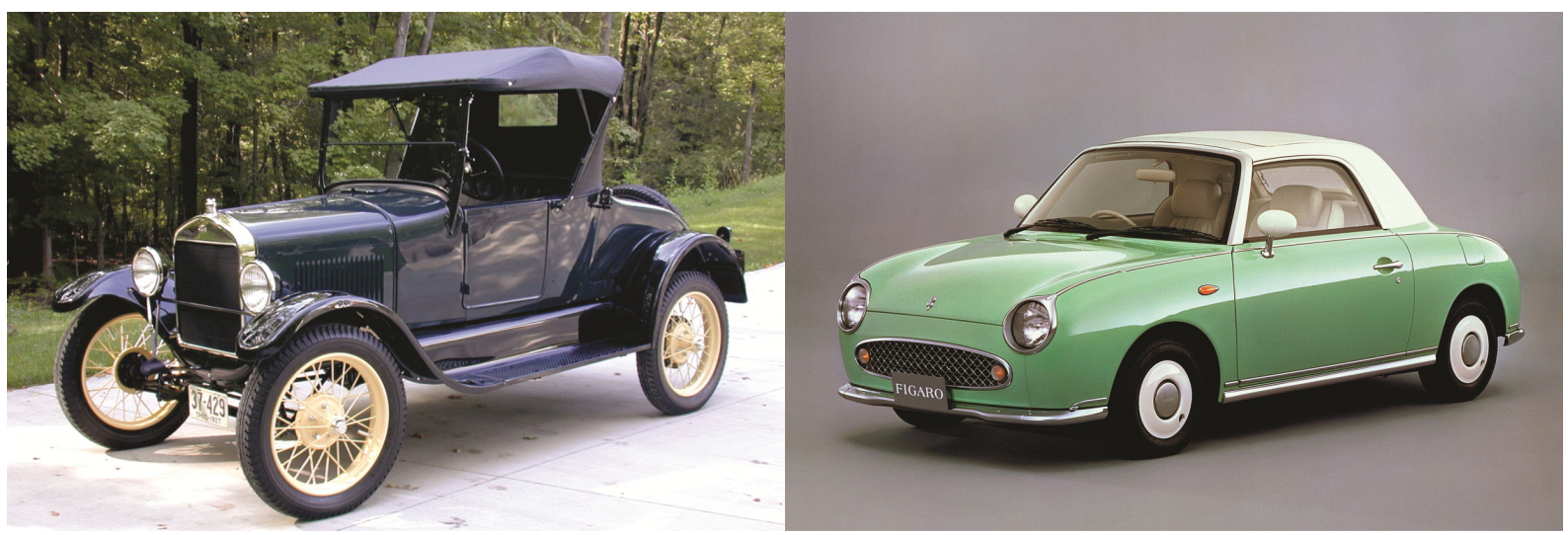

Fig. 2 FORD modelo T e Nissan Figaro 1989 - Fonte do autor

Assim, entendemos que em determinadas ocasiões o designer é mais que um criador de produtos, é também, um realizador ou materializador de desejos, pois através da sua linguagem de criação, ele pode implantar conceitos, que ultrapassam o valor econômico dos objetos, gerando um valor especial, um novo significado.

É clara a percepção que o design está sempre ligado a algum tipo de movimento, seja ele social, econômico ou cultural, sempre correlacionado diretamente ao comportamento de cada sociedade. Entender esta ligação, como ela surge, os mecanismos que a controlam, pode nos ajudar, enquanto designers, a compreender que os sentimentos de pertença de uma comunidade e suas influências, determinam os costumes, o modo de vida, hábitos e desejos, que por sua vez, resultam em necessidades e estas geram os artefatos que estão carregados de significados na criação da historicidade das pessoas ou de grupos sociais.

Para tornar-se objeto de consumo é preciso que o objeto se torne signo, quer dizer, exterior de alguma forma a relação da qual apenas significa - portanto arbitrário e não 
coerente com esta relação concreta, mas adquirindo coerência e consequentemente sentido em uma relação abstrata e sistemática com todos os outros objetos-signos. É então que ele se 'personaliza', que entra na série, etc.: é consumido - jamais na sua materialidade, mas na sua diferença. (BAUDRILLARD, 2006, p. 207).

Abraham Moles (1981) referencia este pensamento de Baudrillard ao afirmar que os objetos são portadores de signos e valores da vida cotidiana. Mudam os valores da vida - mudam os signos mudam os objetos, ou seja, a significação que damos às coisas está diretamente relacionada ao nosso repertório de vida, e às variáveis que perpassam o tempo todo a relação homem/objeto.

Francesco Zurlo (2010) relata que o design se ocupa em dar sentido ao sistema dos objetos que nos circunda. Cada ser humano vive os objetos, sustenta-os com a própria energia psíquica, vê-os como parte de si, da própria vivência. Para ele, na sociedade contemporânea, essa extensão da vida psíquica aos objetos e também às relações das pessoas, dá relevância ao papel de quem dá forma aos mesmos: o design. E forma, hoje, não é mais somente a manifestação tangível e material de um objeto com alguma função, mas o canal de acesso a um sistema de significados que vai bem além da sua estrutura física.

O diferencial do design do século XXI está na inovação de sua gestão. Pensando no design como uma ferramenta para o mercado, Verganti (2012) afirma que gestores de empresas e/ou instituições podem criar ou implementar estratégias de inovação baseadas no design, que irão gerar ações, produtos ou serviços com significados completamente novos, e é esta novidade que os tornam necessários e desejados pelas pessoas. $\mathrm{O}$ autor considera que estes significados são tão diferentes de tudo que está no mercado, que chegam a surpreender, apaixonando as pessoas que os admiram. Ainda segundo ele, a inovação orientada pelo design tem por finalidade a geração de novos significados, já que a palavra design significa "dar sentido às coisas". Pensando na ressignificação como uma ferramenta estratégica para o design, poderemos utilizar as ideias de Verganti (2012) além do campo dos negócios, abarcando as esferas social e cultural.

Nosso interesse pelo estudo da ressignificação nasceu com a pesquisa durante $o$ desenvolvimento da dissertação de mestrado ${ }^{1}$. Nosso objetivo era determinar dois pontos importantes: 1. Como se processava a ressignificação e 2 . Seria possível ao designer manipular intencionalmente as variáveis contidas num objeto/artefato, a ponto de promover uma ressignificação? Tivemos êxito ao comprovar as duas questões através das pesquisas bibliográficas e de pesquisa quantitativa survey ${ }^{2}$, que nos proporcionou a obtenção de dados e informações que indicavam a opinião de um grupo de pessoas acerca das nossas duas suposições.

Assim, partindo do princípio que o designer é um manipulador de signos, acreditamos que esta manipulação pode ser uma ferramenta estratégica eficaz para o design. Se encontrarmos referencial teórico e prático que nos possibilitem manusear este conhecimento intrínseco que rege esta sutil relação entre a metodologia de design e o desejo humano, ligada à sua questão principal que é o significado que damos aos objetos, poderemos ser capazes de articular melhor os processos de gestão do design em todos os níveis, sejam eles culturais, sociais ou econômicos, gerindo estratégias mais eficazes.

A partir da investigação dos processos de criação de significados na sociedade atual (ato de ressignificar), acreditamos que será possível ao designer criar estratégias capazes de solucionar questões culturais, sociais ou econômicas.

\footnotetext{
${ }^{1}$ BELCHIOR, Camilo de Lelis. Reciclando os sentidos: O papel do design na ressignificação dos objetos. Dissertação (mestrado em Design, inovação e sustentabilidade) - Escola de Design da Universidade do Estado de Minas Gerais, (2011).

${ }^{2}$ Survey é um método de pequisa apropriado quando se deseja responder questões do tipo "o quê?", "Por quê?", "Como?" e "Quando?", ou seja, quando o foco de interesse é sobre "o que está acontecendo" ou "como e por que isso está acontecendo".
} 
Portanto, nossa questão de pesquisa busca entender o processo de ressignificação dentro do design como uma ferramenta estratégica, num sentido mais amplo da palavra, ou seja, uma estratégia relacionada a qualquer questão que o design possa atuar e não somente a questões econômicas.

Nosso trabalho tem como objetivo, investigar as diversas relações existentes entre o homem, sua desejabilidade, os significados concedidos aos objetos e o papel do design nesse processo, para entender como estas variáveis são capazes de influenciar e/ou modificar os sentidos que damos aos artefatos e que podem elevar o design ao patamar de um articulador mais completo, sendo ele mais estratégico, tático e operacional, nas mais diversas situações impostas pela vida contemporânea.

Para alcançar nossos objetivos, precisaremos pesquisar como o design interfere na atribuição de valor e sentido aos artefatos, a partir do século XX, principalmente a partir do pós-guerra, quando se constitui a chamada sociedade de consumo, contribuindo na construção da cultura das sociedades; Analisar as transformações nas relações de consumo a partir da metade do século $\mathrm{XX}$ até os dias atuais, de forma a entender a reconstrução de valores e sentidos que nos últimos anos tem alterado o desejo da sociedade contemporânea; Entender como e quando ocorrem as estratégias do design, para compreender onde a ressignificação pode atuar como uma ferramenta; Analisar, nos vários casos disponíveis no mercado, possíveis padrões estratégicos que utilizaram a ressignificação como ferramenta principal de ação, produto ou serviço; Elaboração e aplicação de experimentação prática onde a ressignificação será utilizada como uma ferramenta estratégica do design num contexto social específico.

\section{Construindo uma metodologia}

O trabalho terá como premissa metodológico a Hermenêutica de Profundidade de John B. Thompson (2011), por ser uma metodologia que oferece uma abertura investigativa, nos possibilitando uma análise em três fases, relacionadas à vida quotidiana:

1. Análise sócio histórica (analisa situações espaço-temporais, campos de interação, instituições e estruturas sociais e meios de transmissão);

2. Análise Formal ou Discursiva (Possibilita análises semióticas, da conversação, sintáticas, narrativas e argumentativas);

3. Interpretação/Re-interpretação (possibilita a compreensão de construções que tipicamente representam algo, referem-se a algo, dizem alguma coisa sobre algo).

\section{Formas de Investigação Hermenêutica}

Hermenêutica da Vida Quotidiana - Interpretação da Doxa

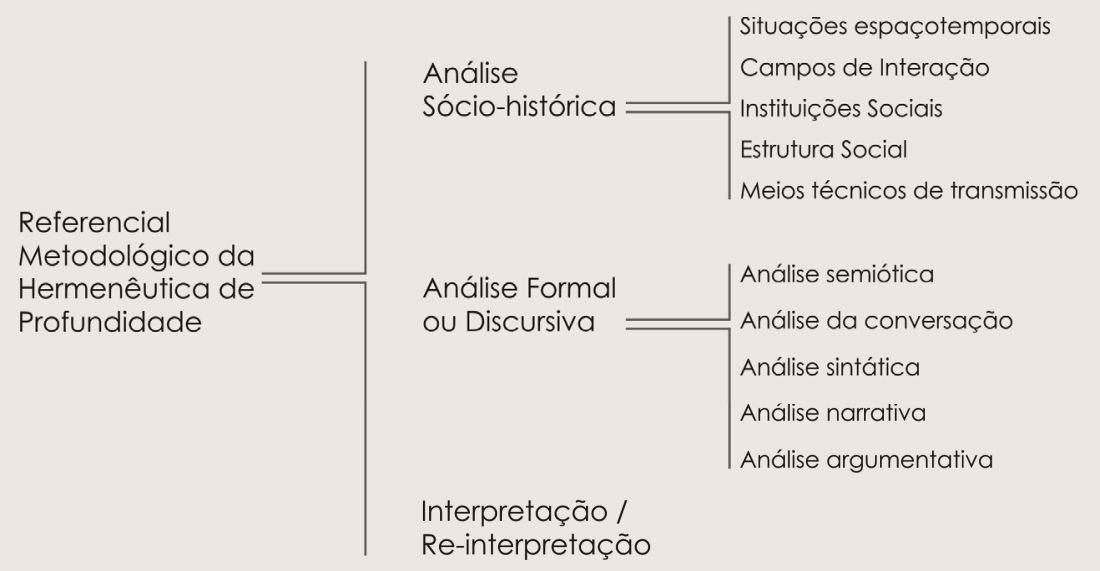

Fig. 3 Formas de Investigação Hermenêutica. Fonte: (THOMPSON, 2011, pg.365) 


\section{A partir desta metodologia propomos a articulação com 04 eixos:}

Eixo 1 - Design, cultura e sociedade: utilizaremos a primeira fase da HP para analisar o processo de surgimento das formas simbólicas e suas relações na cultura do design e como acontece a sua comunicação na sociedade de um modo geral. Associado a Thompson, utilizaremos o trabalho de Eric Hobsbawm (2016), Adrian Forty (2007), Nikolaus Pevsner (2001), entre outros, para uma análise sócio-histórica mais assertiva, como postulado na primeira fase da Hermenêutica de profundidade de Thompson (2011).

Formas simbólicas não subsistem num vácuo, elas são produzidas, transmitidas e recebidas em condições sociais e históricas específicas. O objetivo da análise sócio histórica é reconstruir as condições sociais e históricas de produção, circulação e recepção das formas simbólicas. (THOMPSON, 2011, p. 366).

Com a utilização da análise sócio-histórica seremos capazes compreender as condições de produção, circulação e recepção de algumas formas simbólicas que compõem a cultura do design na contemporaneidade.

Eixo 2 - Consumo e desejo na contemporaneidade: Pesquisamos os processos e sentidos do consumo no século XXI propondo trabalhar com a perspectiva de autores como: Deyan Sudjic (2010), Melinda Davis (2003), Donald Norman (2008), Gilles Lipovetsky (2015), Grant McCracken (2012), entre outros, que investigam as transformações nas relações de consumo na atualidade e definem o consumo como algo diretamente ligado à felicidade humana, a partir do qual foi construída uma nova percepção sobre o papel da felicidade na vida dos indivíduos. O seu significado foi alterado, estando relacionado agora a uma busca permanente da realização pessoal. Instaura-se aí uma nova cultura do desejo, "Esses pequenos prazeres vêm preencher uma necessidade muito maior de realização pessoal" (LIPOVETSKY, 2015).

Nesta fase, ainda contaremos com o auxílio da segunda fase da Hermenêutica de Profundidade, a análise Formal ou Discursiva que poderá nos levar ao entendimento de como questões ligadas ao consumo estão contribuindo para uma alteração nos padrões da desejabilidade humana.

Formas simbólicas são os produtos de ações situadas que estão baseadas em regras, recursos, etc., disponíveis ao produtor; mas elas não são também algo mais, pois elas são construções simbólicas complexas, através das quais algo é expresso ou dito. Formas simbólicas são produtos contextualizados e algo mais, pois elas são produtos que, em virtude de suas características estruturais, têm capacidade, e têm por objetivo, dizer alguma coisa sobre algo. É esse aspecto adicional e irredutível das formas simbólicas que exige um tipo diferente de análise, uma maneira diferente de olhar as formas simbólicas. (THOMPSON, 2011, p. 369).

Entre os vários métodos empregados na análise formal ou discursiva, utilizaremos a análise semiótica, que Thompson (2011) entende como o estudo das relações entre os elementos que compõem a forma simbólica, ou o signo, e das relações entre esses elementos e os do sistema mais amplo, do qual a forma simbólica, ou signo, podem ser parte.

Eixo 3 - Estratégia e Design: Pretendemos pesquisar sobre as questões estratégicas do design e como elas estão associadas com a ressignificação, a partir do que Roberto Verganti (2012) chama de Inovação Radical de Significados. Trabalharemos também a visão de autores como Francesco Zurlo (2010), Marc Gobé (2010), Tim Brown (2010), Brigitte Borja de Mozota (2011), entre outros, que conceituam o design estratégico a partir de uma perspectiva mais ampla, partindo do entendimento que nos dias atuais o designer não projeta apenas artefatos desprovidos de significação ou que apenas resolvam problemas funcionais. 
O design como processo proporciona um movimento de transformação, pois é um sistema aberto que permite e propõe diversos pontos de vista, modelos interpretativos articulados e várias prospectivas disciplinares. Por meio da coletividade de pensamento típica do design, que por sua vez será traduzida na produção de valor para clientes, parceiros, colaboradores e demais stakeholders, o design estratégico tem uma capacidade própria de habilitar um processo dialógico entre vários atores e traz como característica um agir estratégico como causa e efeito de um processo coletivo e interativo que pode modificar a realidade. (ZURLO, 2010).

O design contemporâneo busca projetar toda uma cadeia de valor, incluindo principalmente a atribuição dos sentidos atrelada às estratégias. Assim, para finalizar o capítulo, buscaremos no mercado casos onde a ressignificação tenha contribuído para modificar problemas, necessidades, ou outra situação que necessite de uma resolução efetiva, sejam elas de produto ou serviço, ainda que de forma involuntária ou sem um aparato metodológico, para aferirmos onde e como se processou a ressignificação e seus possíveis resultados.

Nossa ideia é analisar 01 caso representativo, que possa confirmar a teoria. Usaremos o método de Estudo Descritivo:

O estudo descritivo possibilita o desenvolvimento de um nível de análise em que se permite identificar as diferentes formas dos fenômenos, sua ordenação e classificação. É um tipo de estudo que permite ao pesquisador a obtenção de uma melhor compreensão do comportamento de diversos fatores e elementos que influenciam determinado fenômeno. (Oliveira, 2001, pag.114).

Eixo 4 - Uma investigação qualitativa: Para validarmos nossa teoria, que a ressignificação pode ser utilizada como uma ferramenta estratégica do design, com o intuito de auxiliar na resolução de questões onde a contribuição do design faz-se necessária, pretendemos fazer a aplicação de uma experimentação prática. Importante ressaltar que, como foi dito anteriormente, este trabalho pretende demonstrar que a ressignificação, como uma estratégia do design, pode atuar numa variedade de possibilidades que não sejam exclusivamente para desdobramentos econômicos, numa primeira instância.

Para nos auxiliar na comprovação da nossa tese, partiremos do projeto de pesquisa "Design para autoestima - ressignificar para incluir", coordenado pela professora Rita Ribeiro, aprovado nos Editais Universais CNPq e FAPEMIG no ano de 2016, desenvolvido em parceria com a Associação Mineira de Reabilitação (AMR). Por meio deste projeto buscamos a aplicação prática de nossa teoria.

A AMR atende cerca de 500 crianças e adolescentes carentes com deficiência física ocasionadas em sua maioria por paralisia cerebral e outras síndromes neurológicas. Atua com uma equipe multidisciplinar de profissionais especializados nas áreas de Fisioterapia, Terapia Ocupacional, Fonoaudiologia, Psicologia, Musicoterapia, Esporteterapia, Odontologia, Serviço Social, Neurologia, Ortopedia e Cirurgia Ortopédica. A AMR é considerada referência no atendimento multidisciplinar de reabilitação motora no estado de Minas Gerais, oferecendo atendimento a Belo Horizonte e mais 22 municípios da Região Metropolitana. 


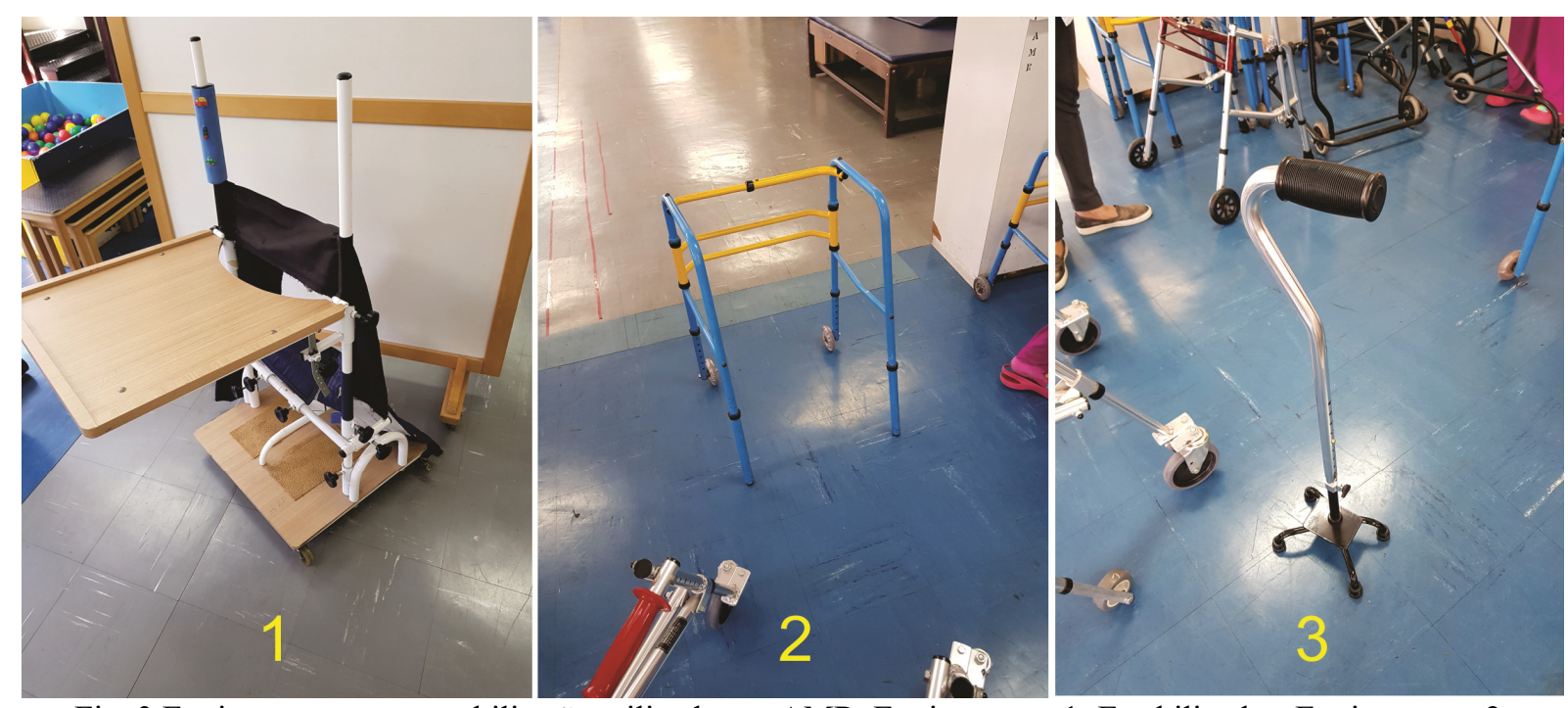

Fig. 3 Equipamentos para reabilitação utilizadas na AMR. Equipamento 1: Estabilizador; Equipamento 2: Andador; Equipamento 3: Bengala de apoio.

Para nos dar um suporte analítico e metodológico nesta aplicação prática, utilizaremos a terceira e última etapa da Hermenêutica de profundidade chamada de Interpretação/Re-interpretação.

O processo de interpretação, mediado pelos métodos do enfoque da HP, é simultaneamente um processo de reinterpretação. Pois, as formas simbólicas que são o objeto de interpretação são parte de um campo pré-interpretado, elas já são interpretadas pelos sujeitos que constituem o mundo sócio-histórico. Ao desenvolver uma interpretação que é mediada pelos métodos do enfoque da HP, estamos reinterpretando um campo pré-interpretado; estamos projetando um significado possível que pode divergir do significado construído pelos sujeitos que constituem o mundo sócio-histórico. (THOMPSON, 2011, p. 376).

Este projeto, portanto, pretende trabalhar nas possibilidades de intervenção do design, usando a ressignificação de forma estratégica para atuar na autoestima destas crianças portadoras de algum tipo de deficiência física, nos seus familiares e seus cuidadores (profissionais de reabilitação). Nossa proposta é pensar em outro tipo de atuação do design, no campo das práticas de inclusão social, voltado à construção de artefatos (ver fig. 3) que são indispensáveis às pessoas com deficiências, ressignificando estes artefatos, promovendo assim o aumento da autoestima de seus usuários.

\section{Structuring a methodology to analyze resignification as a strategic design tool.}

Abstract: Various innovations linked to the design have been developed over decades and many are linked directly or indirectly to questions of meaning, or rather the relation of meaning or meanings we attach to objects, artifacts or things in general. To think that if we can assign meanings, we can also change them from their initial meaning, opens up an infinite range of possibilities for design. In this context, re-meaning is to provide a new meaning to the object by changing its concept, its original perception or interpretation. It is to make the object coherent for the subject, under a new point of view, transforming it into the current context. Reflecting on this issue has led us to believe that redetermination can also be understood as a tool for design, giving it more strategic elements. The study of resignification as a strategic design tool is the central theme of Camilo Belchior's doctoral thesis and this article deals with how the methodology of his work was structured. 


\section{Referências bibliográficas}

BAUDRILLARD, Jean. 0 sistema dos objetos. São Paulo: Perspectiva, 2006.

BROWN, Tim. Design thinking: uma metodologia poderosa para decretar o fim das velhas ideias. Rio de Janeiro: Elsevier, 2010.

CARDOSO, Rafael. Design para um mundo complexo. São Paulo: Cosac Naify, 2013.

DAVIS, Melinda. A nova cultura do desejo. Tradução Eliane Fraga e Sylvio Gonçalvez. Rio de Janeiro: Record, 2003.

FORTY, Adrian. Objeto de desejo: design e sociedade desde 1750. São Paulo: Cosac Naify, 2007.

GOBÉ, Marc. Brandjam: o design emocional na humanização das marcas. Rio de Janeiro: ROCO, 2010.

HOBSBAWM, Eric. A era do capital, 1848 - 1875. São Paulo: Paz e Terra, 2016.

LIPOVETSKY, Gilles. A estetização do mundo: Viver na era do capitalismo artista. São Paulo: Companhia das Letras, 2015.

MCCRACKEN, Grant. Cultura e Consumo II: mercados, significados e gerenciamento de marca. Rio de Janeiro: Muad, 2012.

MAZOTA, Brigitte Borja de. Gestão do design: usando o design para construir valor de marca e inovação corporativa. Porto Alegre: Bookman, 2011.

MOLES, Abraham. Teoria dos objetos. Rio de Janeiro: Edições Tempo Brasileiro, 1981.

NORMAN, Donald A. Design emocional: por que adoramos (ou detestamos) os objetos do dia-a-dia. Tradução Ana Derió. Rio de Janeiro: Rocco, 2008.

OLIVEIRA, Silvio Luiz de. Tratado de metodologia científica. São Paulo: Pioneira, 2001.

PEVSNER, Nikolaus. Origens da arquitetura moderna e do design. São Paulo: Martins Fontes, 2001.

SUDJIC, Deyan. A linguagem das coisas. Tradução Adalgisa C. Silva. Rio de Janeiro: Intrínseca, 2010.

THOMPASON, John B. Ideologia e cultura moderna: teoria social crítica na era dos meios de comunicação de massa. Petrópolis, RJ: Vozes, 2011.

ZURLO, Francesco. Entrevista. São Leopoldo, 2006. Disponível em: <http://www. ihuonline.unisinos.br/>. Acesso em: 08 jan. 2010.

VERGANTI, Roberto. Design-driven innovation: mudando as regras da competição - a inovação radical do significado de produtos. São Paulo: Canal Certo, 2012. 